\title{
Istutuksen tasaisuuden merkitys perunan tuotannossa
}

\author{
EERO VARIS \\ Hankkijan kasvinjalostuslaitos, Anttilan koetila, Hyrylä
}

ILMO LANNETTA

Maatalouskoneiden tutkimuslaitos, Rukkila

Saapunut 8.4.1974

\section{The role of planting accuracy in potato production}

\author{
Eero Varis \\ Plant Breeding Institute of Hankkija, Experimental Farm Anttila, Hyrylä, Finland \\ ILMO LANNETTA \\ Finnish Research Institute of Agricultural Engineering, Rukkila, Finland
}

\begin{abstract}
The effects of inaccurate planting on the yield and quality of Realta and Ijsselster potatoes were studied from 1970-1973 using 3 treatments: 1) accurate $30 \mathrm{~cm}, 2)$ systematically varying $(0-5-10 \ldots-60 \mathrm{~cm}$ at random), 3) varying at random (viz. Figure 1).

Inaccurate plantings affected tuber yield adversely in only one of the trials, where the yield level was low.

Starch content was $0.3-0.7$ per cent lower in the case of the inaccurate plantings.

Inaccurate plantings resulted in an increased proportion of large tubers.

Results of specific gravity sorting showed no clear effects. Some concentration into middle S.G. classes was, however, characteristic of the inaccurate plantings.
\end{abstract}

Perunan istutuksessa on vanhastaan pidetty sääntönä mahdollisimman tasaisen istutuksen paremmuutta. Tätä sääntöä noudattaen on myös perunan istutuskoneissa käytetty joko kuppi- tai lokeroperiaatetta tämän päämäärän saavuttamiseksi. Puoliautomaattiset istutuskoneet, joissa perunat asetetaan käsin kuppeihin tai lokeroihin, ovat kuitenkin hitaita ja ihmistyötä vaativia. Automaattiset kuppielevaattorikoneet ovat taas osoittautuneet, kovakouraisiksi rikkoen sekä perunoita että varsinkin ituja.

Viime vuosikymmenen lopulla kantautui Suomeen tietoja englantilaisesta kaksois-kumihihnasyötöllä varustetusta istutuskoneesta. Siinä perunat valuvat perunasäiliön pohjassa sijaitsevan kumirullan sääteleminä kahdelle kumiselle hihnalle, jotka liikkuvat eri nopeudella ja muodostavat keskenään kou- 
run. Tämä liikkuva kouru siirtää perunat suhteellisen tasaiseen järjestykseen ja syöttää ne vakoon. Tämän koneen etuina ovat hellävaraisuus ja nopeus, sillä sitä voidaan käytännössä ajaa n. $6 \ldots 8 \mathrm{~km} / \mathrm{h}$-vauhtia eli kaksi kerțaa niin nopeasți kuin kuppisyöttöisiä istutuskoneita. Koneen haittana pidetään epätasaista istutusta (JARvis ja PALMER 1973).

Tämän tutkimuksen tarkoituksena oli selvittää epätasaisen istutuksen aiheuttamia muutoksia perunasadon määrässä ja laadussa.

Aineisto ja sen käsittely

Koeaineisto jakaantuu kahteen osaan, vuosien 1970-1971 3 koetta ja vuosien $1972-19733$ koetta.

Vuosien 1970-1971 koesarjassa oli mukana kaksi koejäsentä:

1. Tasainen istutus $30 \mathrm{~cm}: \mathrm{n}$ välein

2. Systemaattisesti vaihteleva, mukulaväli $0-60 \mathrm{~cm}$ joka $5 \mathrm{~cm}: n$ välein $(0-5-10-15 \ldots-60)$ satunnaisessa järjestyksessä.

Vuosien 1971-1972 kokeisiin lisättiin vielä koejäsen

3. Satunnaisesti vaihteleva, johon mukulavälit saatiin kaksois-hihnasyöttökoneen laboratoriokokeesta Maatalouskoneiden Tutkimuslaitokselta.

Piirroksessa 1 on tarkemmin esitetty eri koejäsenten mukulavälien prosenttiset jakaumat.

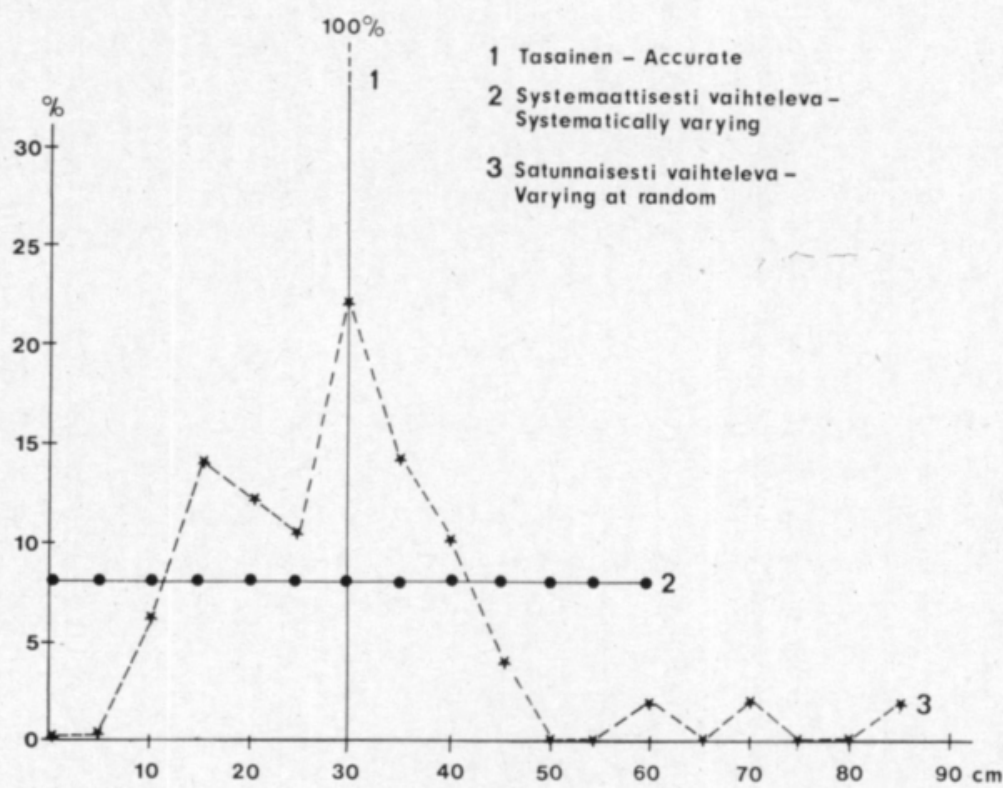

Piirros 1. Istutusetäisyyden prosentuaalinen jakautuminen eri koejäsenissä.

Figure 1. The percentage distribution of seed potato spacings in the different treatments. 
Koeruudut olivat 2-rivisiä, 26 mukulaa rivissä. Kerranteita oli 4, lajikkeita 2: Realta tai Rekord ja Ijsselster (vähämukulainen ja runsasmukulainen). Kokeita järjestettiin Hankkijan kasvinjalostuslaitoksen Anțilan koetilalla vuosina 1970-73 yhteensä $5 \mathrm{kpl}$ sekä Maatalouskoneiden Tutkimussäätiön hallinnassa olevalla Kosken tilalla Karkkilassa v. 1973 yksi koe. Maalaji vaihteli eri kokeissa ollen joko hietaa, hietasavea tai multamaața.

Seuraavat havainnot esitetään:

1. Mukulasato (tn/ha).

2. Tärkkelys-\%. Tärkkelysmääritykset tehtiin 2 kerranteesta käyttäen $5 \mathrm{~kg}: n$ näytettä. Mukuloiden paino $+18^{\circ} \mathrm{C}$ vedessä punnitțiin Mettler K 7-sähkövaa'alla. Tärkkelyspitoisuus määritettiin Hals \& Bucholzin asteikosta.

3. Kokojakautuma. Ruutusadot lajiteltiin 40 ja 55 mm:n seuloilla.

4. Ominaispainojakautuma. Ruutusadot lajiteltiin viiteen luokkaan ominaispainon mukaan $+18{ }^{\circ} \mathrm{C}$ suolavesiliuoksissa, joiden ominaispainot olivat $1.065,1.075,1.085$ ja 1.095 . Tulokset esitetään paino-\%:ina.

Kokeiden tilasțollisessa käsittelyssä käytettiin varianssianalyysejä, jotka laskettiin Keskusosuusliike Hankkijan ATK-osastolla. Erojen merkitsevyys on ilmaistu tavalliseen tapaan.

\section{Tulokset ja tarkastelu}

Mukulasato

Varianssianalyysin mukaan (Taulukko 1) istutuksen epätasaisuus vaikutti ensimmäisessä koesarjassa jopa lievästi mukulasatoa lisäävästi (Taulukko 3).

Taulukko 1. Varianssianalyysi istutuksen tasaisuuskokeista $1970-71$.

Table 1. Analysis of variance of the trials in 1970-71.

\begin{tabular}{|c|c|c|c|c|}
\hline $\begin{array}{l}\text { Tekijä } \\
\text { Factor }\end{array}$ & $\begin{array}{c}\text { Mukulasato } \\
\text { Tuber yield } \\
\text { tn/ha }\end{array}$ & $\begin{array}{c}\text { Tärkkelys-\% } \\
\text { Starch } \\
\text { content } \\
\%\end{array}$ & $\begin{array}{c}\text { Koko- } \\
\text { jakautuma } \\
\text { Size } \\
\text { distribution } \\
\%\end{array}$ & $\begin{array}{c}\text { Ominaispaino- } \\
\text { jakautuma } \\
\text { S. G. } \\
\text { distribution } \\
\%\end{array}$ \\
\hline $\begin{array}{l}\text { A. Koe - Trial .............. } \\
\text { B. Istutustapa - }\end{array}$ & $* * *$ & $* * *$ & $* * *$ & - \\
\hline Planting method ........ & $(*)$ & $* *$ & $(*)$ & ns \\
\hline C. Lajike - Cultivar ..... & $(*)$ & $* * *$ & $* * *$ & $* * *$ \\
\hline 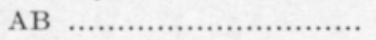 & $(*)$ & ns & ns & - \\
\hline 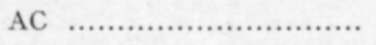 & $(*)$ & * & $(*)$ & - \\
\hline 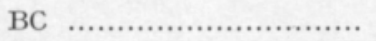 & ns & ns & ns & ns \\
\hline
\end{tabular}


Taulukko 2. Varianssianalyysi istutuksen tasaisuuskokeista 1972-73.

Table 2. Analysis of variance of the trials in 1972-73.

\begin{tabular}{|c|c|c|c|c|}
\hline $\begin{array}{l}\text { Tekijä } \\
\text { Factor }\end{array}$ & $\begin{array}{l}\text { Mukulasato } \\
\text { Tuber yield } \\
\text { tn/ha }\end{array}$ & $\begin{array}{c}\text { Tärkkelys- } \% \\
\text { Starch } \\
\text { content } \\
\%\end{array}$ & $\begin{array}{c}\text { Koko- } \\
\text { jakautuma } \\
\text { Size } \\
\text { distribution } \\
\%\end{array}$ & $\begin{array}{c}\text { Ominaispaino- } \\
\text { jakautuma } \\
\text { S. G. } \\
\text { distribution } \\
\%\end{array}$ \\
\hline A. Koe - Trial .............. & $* * *$ & $* * *$ & $*$ & - \\
\hline B. Istutustapa - & & & & \\
\hline Planting method ........ & ns & $(*)$ & ns & $* *$ \\
\hline C. Lajike - Cultivar ..... & $* * *$ & $* * *$ & $* * *$ & $* * *$ \\
\hline AB $\ldots \ldots \ldots \ldots \ldots \ldots \ldots \ldots$ & ns & ns & ns & - \\
\hline AC $\ldots \ldots \ldots \ldots \ldots \ldots \ldots$ & ns & ns & *** & - \\
\hline BC & ns & ns & * & $* * *$ \\
\hline
\end{tabular}

Taulukko 3. Istutuksen tasaisuuden vaikutus mukulasatoon.

Table 3. Effects of planting method on tuber yield.

Istutustapa

Planting method
$1970-71$

$1972-73$
1 Tasainen - Accurate

31.96

33.48

2 Systemaattisesti vaihteleva - Systematically varying

3 Satunnaisesti vaihteleva - Varying at random ...

Suurin ero - Greatest difference

PME - L.S.D. $(5 \%)$
$-$

1.52

1.86
28.40

28.92

28.01

0.91

Ero oli selvä kahdessa kokeessa, joissa satotaso oli korkea (keskim. 34.72 ja $41.17 \mathrm{tn} / \mathrm{ha}$ ). Sen sijaan kolmannessa kokeessa, missä sadot olivat pienemmät (keskim. 22.26) tasainen istutus oli lievästi parempi. Vuosien 1972-73 kokeissa ei mitään merkitseviä eroja eikä yhdysvaikutuksia todettu (vrt. JARvis ja Palmer 1973).

Lajikkeiden reagoinnissa istutustapaan ei ollut eroa (BC).

Nämä koetulokset viittaavat siihen, että hyvissä kasvuoloissa peruna näyttää pystyvän täyttämään kohtuulliset aukkopaikat. Tämä on todettu myös aukkopaikkojen merkitystä selvittävissä tutkimuksissa. HAGBERG (1948) sai aukkopaikkojen satotappioksi $30-40 \%$ puuțtuvien yksilöiden $\%$-määrästä. Samalla tavalla Hirst ym. (1973) esittävät, että $1 \%$ :n aukkoisuus aiheuttaa vain $0.332 \%$ :n satotappion. USA:ssa JAmES ym. (1973) totesivat samoin aukkopaikkojen satoa alentavan prosentuaalisen vaikutuksen olevan n. 1/3 aukkojen prosenttimäärästä. Tässä selostettavan tutkimuksen tulokset viittaavat lisäksi siihen, että aukkopaikkojen merkitys on riippuvainen satotasosta ja että se pienenee satotason noustessa päinvastoin kuin Svensson (1967) esitti.

Aukkopaikkojen lisääntyessä sadonalennus etenee sekä Svenssovin (1967) että Hirstin ym. (1973) mukaan suoraviivaisesți, mutta James ym. (1973) viittaavat muihin tutkimuksiin, joiden mukaan aukkopaikkojen lisääntyessä niiden suhteellinen satoa alentava vaikutus kasvaisi. 
Istutuksen epätasaisuuden vaikutukset sadon määrään voidaan rinnastaa rivivälin vaihtelun aiheuttamiin muutoksiin. On todettu, että riviväliä voidaan muunnella ilman että mukulasadon määrä juuri muuttuu, jos siemenmukuloiden määrää pinta-alayksikköä kohti ei muuteta (PäTZold 1964, NELSoN 1967). Ei ole syytä olettaa, etteikö sama säänțö pätisi myös, kun yksittäisten kasvien väliä penkissä muunnellaan kohtuullisissa rajoissa. Koejäsen 2:n hyvä sato viittaa jopa siihen, että systemaattisesti vaihteleva istutusväli olisi kasvuston sadontuottokyvyn kannalta edullisempi kuin täysın tasainen istutus. Tämä voidaan selittää siten, että eri vuosina, jopa eri aikoina kesästä, kasvuston optimaalinen kasvutiheys on erilainen. "Säännöllisesti epäsäännöllisessä» kasvustossa on aina osa optimaalisessa tiheydessä, mistä syystä koko kasvusto voi yltää jopa parempaan kokonaissatoon kuin tasaisesti istutettu täysin homogeeninen kasvusto.

\section{Tärkkelyspitoisuus}

Tärkkelyspitoisuuden lievä aleneminen näytti olevan seurauksena epätasaisesta istutuksesta (Taulukko 4). Tämä johtunee siitä, että harvoissa paikoissa yksilöiden varsisto rehevöityy runsaammasta tilasta johtuen ja suuri osa yhteyttämistuloksista kuuluu siihen. Mukuloiden saatavissa on puolestaan runsaammin ravinteita ja vettä, mistä syystä ne kasvavat kookkaiksi ja vesipitoisiksi.

Taulukko 4. Istutuksen tasaisuuden vaikutus tärkkelyspitoisuuteen.

Table 4. Effects of planting method on starch content.

1. Tasainen - Accurate

2. Systemaattisesti vaihteleva Systematically varying

3. Satunnaisesti vaihteleva - Varying at random ...

Tärkkelyspitoisuuden lievä aleneminen korvautuu kuițenkin, mikäli tasaisuuden kustannuksella voidaan istuttaa nopeammin ja hellävaraisemmin ja siten saada peruna nopeasti kosteaan maahan. Täten voitetaan lisää kasvuaikaa keväästä. Hellävarainen istutus puolestaan vähentää itujen katkeilemisen aiheuttamaa kasvun myöhästymistä.

\section{Kokojakautuma}

Epätasainen istutus näytti johtavan isojen mukuloiden määrän lisääntymiseen ja vastaavasti keskikokoisten määrän pienenemiseen (Taulukko 5). 
Taulukko 5. Istutuksen tasaisuuden vaikutus mukuloiden kokojakautumaan (\%). Table 5. Effects of planting method on size distribution.

\begin{tabular}{|c|c|c|c|}
\hline & $\begin{array}{c}\text { Yli } \\
\text { Over } \\
55 \mathrm{~mm}\end{array}$ & $\begin{array}{c}40-55 \\
\mathrm{~mm}\end{array}$ & $\begin{array}{c}\text { Alle } \\
\text { Under } \\
40 \mathrm{~mm}\end{array}$ \\
\hline \multicolumn{4}{|l|}{$1970-71$} \\
\hline $\begin{array}{l}\text { 1. Tasainen }- \text { Accurate } \\
\text { 2. Systemaattisesti vaihteleva }-\end{array}$ & 25 & 61 & 14 \\
\hline 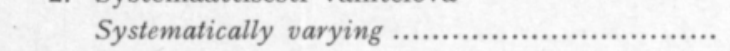 & 30 & 56 & 14 \\
\hline Ero - Difference & 5 & 5 & 0 \\
\hline 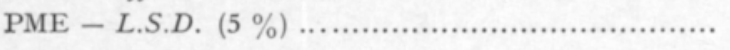 & 6 & 6 & ns \\
\hline \multicolumn{4}{|l|}{$1972-73$} \\
\hline 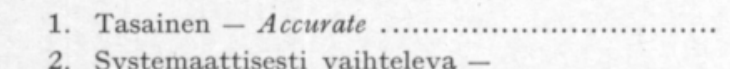 & 22 & 54 & 24 \\
\hline 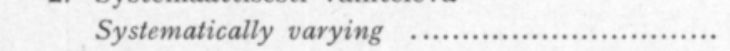 & 26 & 50 & 24 \\
\hline 3. Satunnaisesti vaihteleva - Varying at random & 25 & 51 & 24 \\
\hline Suurin ero-Greatest difference & 4 & 4 & 0 \\
\hline PME - L.S.D. $(5 \%)$................ & ns & ns & ns \\
\hline
\end{tabular}

Tämä on normaali seuraus aukkopaikkojen runsaasta kasvutilasta. Tiheissä paikoissa mukulaluku todennäköisesti sen verran väheni, ettei pienten mukuloiden määrä lisääntynyt.

Ominaispainojakautuma

Koejäsenessä 2 1972-73 oli merkkejä mukuloiden keskittymisestä keskimmäiseen ominaispainoluokkaan, mutta ei kuitenkaan tilastollisesti merkitsevästi (Taulukko 6). Koejäsenessä 3 oli taas havaittavissa siirtymistä alempiin ominaispainoluokkiin, kuten tärkkelyspitoisuuskin osoitti.

Taulukko 6. Istutuksen tasaisuuden vaikutus ominaispainojakautumaan $(\%)$.

Table 6. Effects of planting method on S.G. distribution.

\begin{tabular}{|c|c|c|c|c|c|}
\hline & $\begin{array}{l}\text { Alle } \\
\text { Under } \\
1.065\end{array}$ & $\begin{array}{l}1.065- \\
1.075\end{array}$ & $\begin{array}{l}1.075- \\
1.085\end{array}$ & $\begin{array}{l}1.085- \\
1.095\end{array}$ & $\begin{array}{l}\text { Yli } \\
\text { Over } \\
1.095\end{array}$ \\
\hline 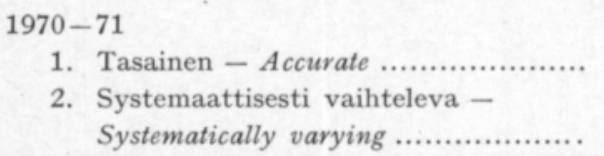 & 0 & 2 & 11 & $\begin{array}{l}31 \\
33\end{array}$ & $\begin{array}{l}56 \\
47\end{array}$ \\
\hline 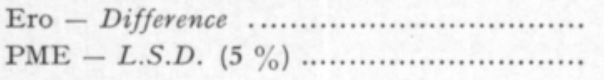 & $\begin{array}{r}0 \\
\text { ns }\end{array}$ & $\begin{array}{r}3 \\
\text { ns }\end{array}$ & $\begin{array}{r}4 \\
\text { ns }\end{array}$ & $\begin{array}{r}2 \\
\text { ns }\end{array}$ & $\begin{array}{r}9 \\
\text { ns }\end{array}$ \\
\hline 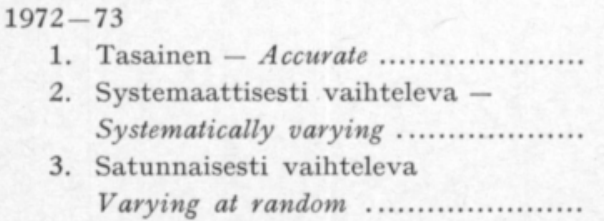 & 10 & 14 & 52 & $\begin{array}{l}29 \\
14\end{array}$ & 1 \\
\hline $\begin{array}{l}\text { Suurin ero }- \text { Greatest difference } \ldots \ldots \ldots \ldots \ldots \\
\text { PME - L.S.D. }(5 \%)\end{array}$ & $\begin{array}{r}7 \\
12\end{array}$ & $\begin{array}{l}18 \\
12\end{array}$ & $\begin{array}{l}13 \\
12\end{array}$ & $\begin{array}{l}19 \\
12\end{array}$ & $\begin{array}{r}7 \\
12\end{array}$ \\
\hline
\end{tabular}


Istutuksen epätasaisuus ei näytä muuttavan sadon sisäistä laatua epäedullisesti, pikemminkin voidaan olettaa sen tasoittuvan. Epätasaisessa kasvustossa nimittäin normaali positiivinen korrelaatio mukulakoon ja ominaispainon välillä murtuu, sillä suurista mukuloista suurin osa kasvaa kasvuston harvoissa paikoissa, missä niiden ominaispaino jää suhteellisen matalaksi. Pienistä mukuloista osa puolestaan kasvaa tiheissä paikoissa, missä niiden ominaispaino on korkeampi kuin tavallisesti (BLEASDALE ja Thompson 1969).

Näiden koetulosten perusteella näyttää olevan mahdollista tinkiä perunan istutuksen tasaisuusvaatimuksesta, mikäli tällä tavalla saavutetaan muita työteknillisiä tai perunan kasvuun liittyviä etuja. Edellytyksenä on kuitenkin riitțävän hyvät kasvuolot ja voimaperäinen viljely, jotka takaavat perunan kyvyn korvata kohtuulliset aukkopaikat.

\section{Yhteenveto}

Perunan istutuksen tasaisuuden vaikutusta Realta-, Rekord- ja Ijsselsterlajikkeiden satoon ja laatuun selvitettiin Hankkijan kasvinjalostuslaitoksen Anttilan koetilalla ja Maatalouskoneiden Tutkimuslaitoksella vuosina 197073 yhteensä kuudessa kokeessa.

Istutuksen epätasaisuus alensi satoa yhdessä tapauksessa, missä satotaso oli matala.

Tärkkelyspitoisuus aleni $0.3-0.7 \%$-yksikköä epätasaisuuden asteesta ja kokeesta riippuen.

Epätasainen istutus aiheutti isojen mukuloiden määrän lisääntymisen keskikokoisten kustannuksella.

Ominaispainojakautumassa ei ollut selviä eroja, mutta v. $1972-73$ oli merkkejä epätasaisen istutuksen vaikutuksesta ominaispainojakautuman keskittymiseen keskimmäisiin ominaispainoluokkiin.

\section{KIRJALLISUUTTA}

Bleasdale, J. K. A. \& Thompson, R. 1969. Some effects of plant spacing and potato quality. Eur. Potato J. 12: 173-187.

Hagberg, A. 1948. Ett försök till uppskattning av skördeminskningen i ett luckigt potatisbestånd. Sv. Utsädesför. Tidskr. 58: 265-269.

Hirst, J. M., Hide, G. A., Stedman, O. J. \& Griffith, R. L. 1973. Yield compensation in gappy potato crops and methods to measure effects of fungi pathogenic on seed tubers. Ann. Appl. Biol. 73: 143-150.

James, W. C., Lawrence, C. H. \& Sнih, C. S. 1973. Yield losses due to missing plants in potato crops. Amer. Potato J. 50: 345-352.

Jarvis, R. H. \& Palmer, G. M. 1973. Effect of type of planter on the growth and yield of maincrop potatoes. Exp. Husb. 24:29-36.

Nelson, D. C. 1967. Effects of row spacing and plant populations on yield and tuber-size of potatoes. Amer. Potato J. 44: 17-21.

PÄtzold, Chr. 1964. Untersuchungen zum Reihenabstand im Kartoffelbau. II. Pflanzenentwicklung. Eur. Potato J. 7: 1-12.

Svensson, B. 1967. Egenskaper och samband hos praktiska potatisodlingar. Lantbr.högsk. Medd. A 70: 1-15. 